\title{
11 SITUAÇões DIFÍCEIS E SEU MANEJO NA ENTREVISTA PARA DOAÇÃO DE ÓRGÃOS
}

\author{
| Paula da Fonseca'; Cláudia Tavares²; Thiago da Silva ${ }^{3}$; Vagner do Nascimento ${ }^{4}$ |
}

\section{RESUMO}

CONTEXTO: A formação em Comunicação de Notícias Difíceis pelos coordenadores avançados em transplantes, não os isenta de lidarem com as situações mais diversas.

OBJETIVO: Identificar os fatores e/ou situações representativas de situações difíceis vivenciadas pelos coordenadores avançados em transplantes; e descrever como manejam tais fatores e/ou situações na condução da entrevista familiar.

MÉTODO: Abordagem qualitativa, estudo hermenêutico. Dados obtidos por entrevista semi-estruturada contendo oito questões abertas dirigidas à 24 coordenadores avançados em transplantes, no período de janeiro a maio de 2012. Utilizada análise do discurso dos sujeitos com base na interpretação proposta na hermenêutica filosófica de Gadamer para organização e compreensão dos dados relatados que foram gravados e, em seguida, transcritos na íntegra. Estudo aprovado pelo Comitê de Ética UFF/HUAP.

RESULTADOS: Identificados como fatores e/ou situações difíceis no momento da entrevista: ambiente; profissionais que falham na comunicação com os familiares; e assistência prestada. Manejos descritos: modo de conduta do entrevistador no trabalho; aspectos emocionais; que envolvem os familiares do potencial doador; lançar mão dos próprios instrumentos de enfrentamento das dificuldades; e ainda o "eu não sei, nunca parei para pensar nisso".

CONCLUSÃO: O afastamento da situação e o tratar sobre o assunto em outro momento lhes permitiu se conhecer melhor, no sentido de saber como agem em sua prática cotidiana laboral.

PALAVRAS-CHAVE: Emoções manifestas; Pessoal de saúde; Transplante; Enfermagem psiquiátrica; Entrevista

\section{RESUMEN}

\section{"Situaciones difíciles y su manejo en la entrevista para la donación de órganos"}

CONTEXTO: La formación en Comunicación de Noticias Difíciles por los coordinadores avanzados en trasplantes no les exime de hacer frente a las situaciones más diversas.

OBJETIVO: Identificar los factores y/o situaciones representativas de situaciones difíciles experimentadas por los coordinadores avanzados en trasplantes; y describir cómo manejan estos factores y/o situaciones en la conducción de la entrevista familiar.

MÉTODO: Enfoque cualitativo, estudio hermenéutico. Los datos furon obtenidos mediante una entrevista semiestructurada conteniendo ocho cuestiones abiertas dirigidas a 24 coordinadores avanzados en trasplantes, durante el período de enero a mayo de 2012. Se utilizó el análisis del discurso de los sujetos basándose en la interpretación propuesta en la hermenéutica filosófica de Gadamer para la organización y la comprensión de los datos reportados, que fueron grabados y, seguidamente, transcritos en su totalidad. Este estudio fue aprobado por el Comité de Ética de la HUAP/UFF.

RESULTADOS: Fueron identificados como factores y/o situaciones difíciles en el momento de la entrevista: entorno; profesionales que fallan en la comunicación con los familiares; y asistencia prestada. Manejos descritos: modo de conducta del entrevistador en el trabajo; aspectos emocionales, que involucran la participación de los familiares del potencial donante; uso de sus propios instrumentos de afrontamiento de las dificultades; y aún el "yo no sé, jamás me detuve a pensar en ello".

CONCLUSIÓN: El alejamiento de la situación y el tratamiento del tema en otro momento les permitió un mejor conocimiento mutuo, en el sentido de saber cómo actúan en su práctica cotidiana laboral.

\section{DESCRIPTORES: Emociones manifiestas; Personal de salud; Trasplantes; Enfermería psiquiátrica; Entrevista}

\begin{abstract}
"Difficult situations management in organ donation interview"

ABSTRACT: The training in Communication of Difficult News by advanced coordinators in transplantation does not exempt them from dealing with the most varied situations.

OBJECTIVE: To identify the factors and/ or situations representative of difficult situations experienced by advanced coordinators in transplantations; and to describe the coping methods and/or situations while conducting family interviews.

METHODS: Qualitative approach, hermeneutic study. Data were obtained from semi-structured interview containing eight open questions directed to 24 advanced coordinators in transplantations, from January to May 2012. We used subject discourse analysis based on the interpretation proposed in the philosophical hermeneutics of Gadamer for organization and understanding of the reported data, which were recorded and, subsequently, fully transcribed. This study was approved by the Ethics Committee of HUAP/UFF.

RESULTS: We have identified the following as difficult factors and/or situations at the time of the interview: environment; professionals who fail to communicate with family members; and assistance provided. Managements described: mode of conduct of the interviewer at work; emotional aspects, which involve the family members of potential donors; to make use of their own instruments to confront the difficulties; and also the "I do not know because I have never thought about that".

CONCLUSION: The estrangement from the situation and dealing with the matter at another time allowed a better understanding of each other, regarding the coping actions in their daily work practice.
\end{abstract}

\section{KEYWORDS: Manifested emotions; Health personnel; Trans- plantations; Psychiatric nursing; Interview}

Submetido em 22-02-2016

Aceite em 30-05-2016

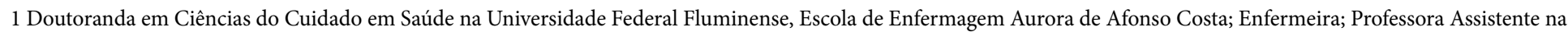
Universidade Estácio de Sá, Estrada do Cabumgui, 786A, 22785-020 Rio de Janeiro/RJ, Brasil, paulaisabellafonseca@gmail.com

2 Pós-Doutora em Educação; Enfermeira; Professora Titular na Universidade Federal Fluminense, Rio de Janeiro/RJ, Brasil, claudiamarauff@gmail.com

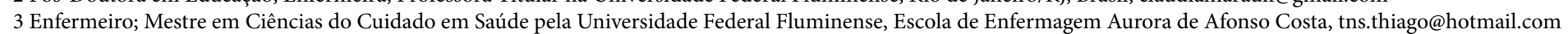
4 Doutorando no Centro Universitário São Camilo; Professor na Escola de Enfermagem da Universidade Estadual do Mato Grosso, Brasil, vagnerschon@hotmail.com

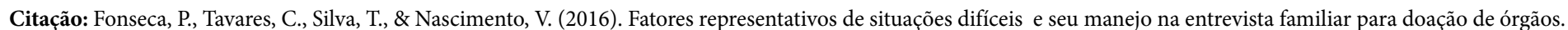
Revista Portuguesa de Enfermagem de Saúde Mental (Spe. 4), 69-76. 


\section{INTRODUÇÃO}

Os denominados coordenadores avançados em transplantes são os responsáveis por realizarem as entrevistas familiares para doação de órgãos. Estes profissionais podem estar vinculados a uma unidade hospitalar representando a Comissão Intrahospitalar de Doação de Órgãos e Tecidos para Transplantes (CIHDOTT), ou mesmo representarem uma Organização de Procura de Órgãos (OPO), esta que está coadunada a uma Central de Notificação, Captação e Distribuição de Órgãos (CNCDO).

Tais dispositivos são regulamentados pelo Sistema Nacional de Transplantes (SNT), que é responsável pelo controle e pelo monitoramento de todos os transplantes de órgãos, tecidos e partes do corpo humano realizados no Brasil. Suas atribuições incluem ações de gestão política, promoção da doação, logística, credenciamento das equipes e hospitais para a realização de transplantes, definição do financiamento e elaboração de portarias que regulamentam todo o processo, desde a captação de órgãos, até o acompanhamento dos pacientes transplantados (Decreto ${ }^{\circ}$ 2268/97).

Embora esta seja a divisão disponível em legislação própria (Portaria no 2600/09), nem todos os estados dispõem de aporte de gente, financeiro, logístico e infraestrutural para fazerem todos os dispositivos supracitados estarem ativos.

Entretanto, independentemente do dispositivo ao qual este profissional esteja ligado, esse ao possuir formação em Comunicação de Notícias Difíceis, idealmente, está habilitado a realizar entrevistas familiares.

Esta formação é citada em estudos e manuais, nacionais e internacionais, que tratam da capacitação e aprimoramento dos profissionais em saúde que atuam no processo de doação de órgãos (Cuiabano, 2010; Moraes, 2013; Pierro, 2015; Programa Avançado em Coordenação de Doação/Transplante, 2007; Roza, 2005).

Porém, tal formação não isenta estes coordenadores de lidarem com as situações mais diversas possíveis na realidade com a qual convivem diariamente nos mais diferentes cenários em que a entrevista possa ocorrer. Desta maneira, além dos dilemas morais que cotidianamente enfrentam neste momento (Fonseca e Tavares, 2015), outros fatores acabam por não corroborar com o desfecho harmonioso ou menos difícil desta etapa tão fundamental do processo de doação de órgãos, que vão desde observações em razão da falta de estrutura no atendimento pré-hospitalar ao doador, falta de condições de cuidar do doador ou de agilizar o processo de doação, exposição do doador na mídia, falta de conscientização por parte dos profissionais em manter a condição clínica do indivíduo em morte encefálica, para tornar-se um potencial doador, até a falta de padronização no trabalho (Lima, 2013). Diante disso, o estudo objetivou: identificar os fatores e/ou situações representativas de situações difíceis vivenciadas pelos coordenadores avançados em transplantes; e descrever como manejam tais fatores e/ ou situações na condução da entrevista familiar.

\section{METODOLOGIA}

Estudo qualitativo de abordagem hermenêutica interpretativa, baseada na perspectiva de Hans-Georg Gadamer - compreende que a interpretação leva a conhecer as condições em que se dá a compreensão; ou seja, procura compreender a própria linguagem e, através dela, o próprio homem, a sua história e existência, pois é através da linguagem que se dá o acesso ao mundo e às coisas (Gadamer, 2008).

O enfoque metodológico da hermenêutica interpretativa possibilita conhecer a tradição do preparo emocional dos profissionais que realizam entrevista familiar para doação de órgãos que, mediante a linguagem utilizada pelos dos coordenadores avançados em transplantes, vem à tona. A tradição é a bagagem de conceitos repassados ao longo dos tempos e condicionam as ações presentes de forma inconsciente, manifestando-se através da linguagem. O Ser é linguagem, e nomeia o mundo. A linguagem caracteriza a relação do Ser com o mundo, diferenciando-o de todos os demais seres vivos. Com a linguagem, o Ser torna-se livre face ao mundo que o circunda, pois é aberta a possibilidade de interpretá-lo, o que lhe traz a dimensão ontológica (Gadamer, 2008). O cenário foi a Central de Notificação, Captação e Distribuição de Órgãos (CNCDO) do estado do Rio de Janeiro, Brasil. Coletou-se dados em janeiro a maio de 2012. Os participantes totalizaram 24 coordenadores de transplantes - 17 enfermeiras, 2 assistentes sociais, 2 médicos e 3 psicólogos - que compõem ou já compuseram a equipe que atua como coordenadora do processo de doação de órgãos. Critério de inclusão utilizado: profissionais que realizaram ou realizam entrevistas familiares para doação de órgãos e que estavam trabalhando no período de coleta de dados na equipe da Central de Transplantes. Critérios de exclusão: profissionais que não realizam ou nunca realizaram entrevistas familiares, e ainda aqueles que mesmo tendo realizado entrevistas familiares não atuassem mais na CNCDO em questão no período de coleta de dados. 
Utilizou-se entrevista semi-estruturada a partir de instrumento composto das seguintes perguntas a respeito das emoções e seu manejo em situações acontecidas na entrevista familiar para doação de órgãos: "Existe algum fator ou situação que torna para você a entrevista mais difícil? Como você lida com ela? ".

Foi utilizada a análise do discurso dos sujeitos com base na interpretação proposta na hermenêutica filosófica de Gadamer, para organização e compreensão dos dados que foram gravados e, posteriormente, transcritos na íntegra. Para resguardar o anonimato dos participantes, seus depoimentos nesse estudo serão identificados com nome de cor.

O estudo foi aprovado pelo Comitê de Ética em Pesquisa do Hospital Universitário Antônio Pedro/UFF sob o $n^{\circ} 321 / 11$ em Nov/2011. Respeita os princípios éticos da Resolução no 466/2012 que trata, no Brasil, sobre os princípios éticos a serem seguidos em pesquisas que envolvem seres humanos.

\section{RESULTADOS}

Nesta sessão serão identificadas as situações difíceis relatadas pelos coordenadores avançados em transplantes num primeiro momento, seguido da descrição dos manejos desses fatores representativos das dificuldades que emergiram na entrevista familiar.

Assim, as situações difíceis vivenciadas no momento da entrevista familiar para doação de órgãos identificadas, giraram basicamente em torno do hospital notificador, ou seja, da unidade hospitalar que notifica um possível doador à CNCDO.

$\mathrm{Na}$ figura 1 abaixo podemos observar quais os elementos contidos no hospital notificador que foram ressaltados como dificultadores do desenvolvimento da entrevista familiar nas falas dos participantes.

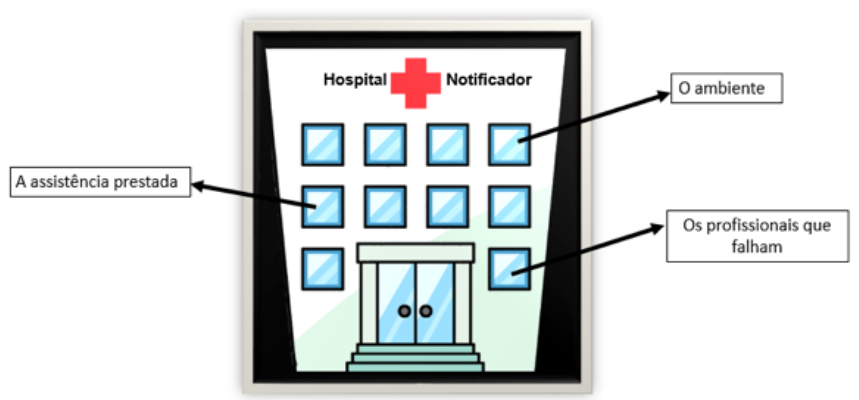

Figura 1 - Fatores representativos de situações difíceis na entrevista familiar para coordenadores avançados em transplantes, 2016
O Ambiente como Dificultador do Desenvolvimento da Entrevista Familiar

A situação dos ambientes em que ocorre a entrevista familiar foi relatada como precária, sendo apontada pelos participantes do estudo como principal elemento dificultador do desenvolvimento da entrevista familiar na unidade notificadora.

O ambiente... o ambiente não adequado, no corredor, a família em pé assim... pessoas que não estão envolvidas naquela situação prestando atenção... eu acho que isso interfere bastante, é bastante desconfortável. E... eu já falei, além disso associado ao estado emocional da família. Eu acho que o ambiente, se você tem uma sala, um local reservado para abordar a família, faz a diferença. Já tive casos em que, tive que fazer no corredor, só tinha duas cadeiras e vários familiares e eu tive que ficar de pé... é uma situação ruim, mas eu também não podia fazer diferente - ficar sentada e falando com a pessoa de pé. Então ali, não tinha outra situação, a gente tentou, mas... isso, isso é desconfortável. Desconfortável porque você não consegue interagir, aí ficam pessoas passando, presta atenção, entendeu? Ficam olhando.... Você tira o teu foco, entendeu? Pessoalmente você também não consegue manter o controle adequado da situação. (Azul Hortência)

Fica claro no relato que a falta de um ambiente adequado que possibilite à família privacidade e tranquilidade, minimamente oportunizando ao familiar sentar-se e estar protegido de ruídos externos, poderia possibilitar um melhor acolhimento por parte da equipe do transplante.

\section{Os Profissionais que Falham Inseridos no Hospital Notificador}

É possível observar que uma abordagem sem preparo adequado, ou seja, sem a técnica de comunicação de más notícias, feita no momento errado, seja antes do fechamento do protocolo de morte encefálica ou no momento em que a família precisa ainda assimilar a situação de morte, causa muitos ruídos e percepções distorcidas acerca da doação por parte dos familiares. Isto leva os entrevistadores a encontrarem, nestes casos, situações recidivamente difíceis, como se pode perceber logo em seguida. Quando o médico que está assistindo o doador, que está ali na manutenção do doador, médico do hospital, não nosso, se antecipa em conversar com a família sobre doação. Isso para mim é o que... é $99 \%$ de chance de dar errado, entendeu? Eu tenho percebido isso, entendeu? De todas as vezes que houve interferência do médico, que está na manutenção, o médico do hospital, que se antecipa em falar com a família sobre a doação, dá errado. (Amarelo Ocre) 
O que é difícil é quando a pessoa não foi preparada. Quando ela.... Foi aberto o protocolo, a família não foi comunicada, o médico avisa que uma cliente, que a pessoa está morta ou então o médico não esclarece que a morte, que é morte encefálica. Ou então, como o que ocorreu com uma médica - ela foi falar com o pai de um menino que se suicidou que ele estava indo, quer dizer, se ele estava indo, e ele não foi, e isso dificulta muito. (Verde Oliva)

\section{A Assistência Prestada pelas Unidades Notificadoras}

Destacou-se aqui a questão principalmente do mau atendimento prestado na unidade notificadora como agente causador de transtornos para os familiares a priori, o que reflete num momento posterior, na entrevista. Este tipo de atendimento contém: falta de leitos para o paciente ainda vivo e sem critérios de morte encefálica, demora para atendimento na emergência do hospital, falta de atenção para os familiares dispensada pela equipe da Unidade de Terapia Intensiva, falta de acolhimento/humanização por parte da equipe do hospital notificador.

A entrevista muito difícil eu acho que é quando a história do paciente no hospital já é uma história difícil "assim", quando você vê uma, um caso que chegou não identificado ou então ficou muito tempo na emergência, então acaba que a gente entra num momento de crise. Então você acaba pegando o resultado de tudo o que aconteceu com aquele paciente ali no hospital, então eu vejo muito isso: às vezes a gente tem péssimas entrevistas, que poderiam ser melhores, em razão do cuidado que aquela pessoa recebeu no hospital desde quando chegou. [...] Eu acho que a gente sofre muito isso, a gente sofre muito com o cuidado não adequado do hospital inteiro. É... as vezes a gente escuta muito isso: poxa vocês são as primeiras pessoas que chegaram e quiseram dar atenção "pra” gente agora que, agora que meu parente está morto vocês querem ter cuidado então isso é péssimo. Então acho que é isso, isso que atrapalha o andamento da entrevista. (Terra Siena Queimada)

Com certeza quando o paciente... quando o potencial doador, ele... a família e ele não estão bem acolhidos no hospital em que eles estão... com certeza. Isso você já chega para entrevista, praticamente já com uma negativa. Porque a primeira (ênfase) coisa que você começa a escutar é tudo que aconteceu, desde quando o paciente deu entrada no hospital. (Verde Inglês)

Quanto aos manejos realizados nos momentos destacados, as falas dos participantes trouxeram os seguintes pontos impressos na Figura 2.

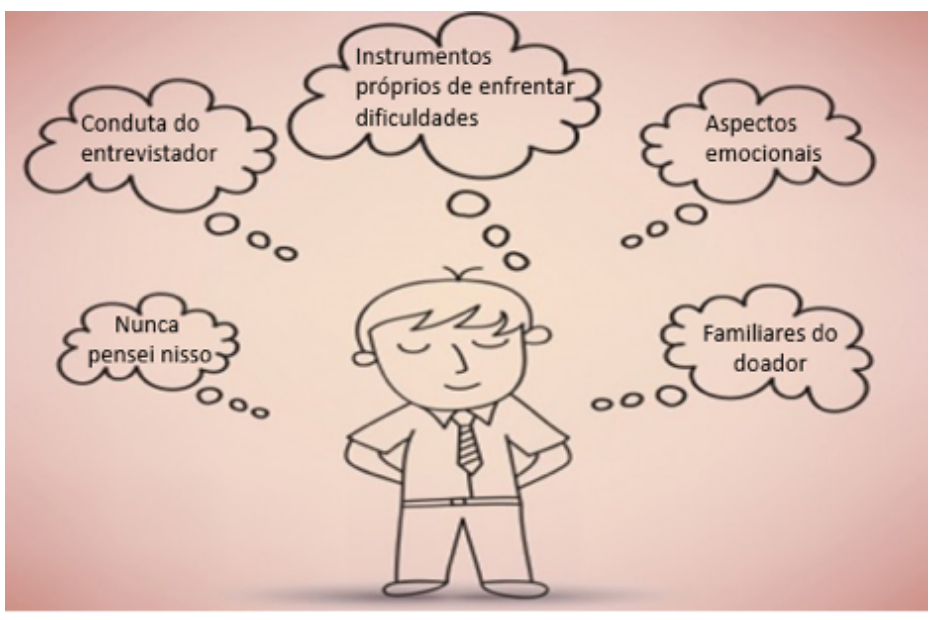

Figura 1 - Manejos das situações difíceis vivenciadas nas entrevistas familiares relatados pelos dos coordenadores avançados em transplantes, 2016

\section{Manejos de Situações Difíceis com Base na Conduta do Coordenador na Entrevista Familiar}

Os participantes declararam que: manejam a situação finalizando a entrevista, mesmo não tendo dado $100 \%$ do seu potencial para finalizá-la; trabalham de maneira não-espontânea, quando a opinião profissional não é respeitada; focam suas perspectivas de superação com o que se pode fazer pelo receptor; nomeiam outra pessoa do plantão para fazer a entrevista familiar quando previamente se sente mal com a história; e, amenizam conflitos entre a equipe do hospital notificador e a da central de transplantes.

Ao dizer como lida com as situações difíceis na entrevista familiar, Azul Cobalto traz a seguinte fala:

[...] eu focava no receptor. Assim, nessa hora eu sentia que não podia fraquejar perto da pessoa [...] E eu focava no receptor [pensando]... tem a criança na fila, mas tem alguém que vai ser beneficiado com essa situação... sempre foi assim. (Azul Cobalto)

A estratégia de pensar no próximo, ou seja, quem receberia a vida que se guardava no corpo do doador, foi citada por três dos participantes entrevistados como forma de enfrentamento da situação difícil.

\section{Manejos de Situações Difíceis com Base nos Aspectos Emocionais}

As falas trouxeram os seguintes manejos das emoções: quando sentem sinais de voz embargada e olhos marejando, os coordenadores avançados em transplantes dão um tempo na entrevista; observam o conforto dos familiares na autorização da doação e respeitam o não dos pais e após, tentam esquecer o sofrimento daquela situação; não se mostram emotivos para passarem confiança, credibilidade do processo, permitindo que a família se abra; e, agradecem por não estarem naquela situação difícil. 
Manejos de Situações Difíceis em Relação aos Familiares do Potencial Doador

Os participantes declararam como manejo da situação a priori: perguntar para a família o que o médico da unidade hospitalar já disse; e, ouvir o desabafo da família.

Para Amarelo Ocre, o contato prévio do médico da unidade notificadora no momento errado ou com informações desencontradas, representa uma situação frequentemente difícil e para manejar esta situação, temos a fala a seguir:

[...] primeira pergunta que faço é: o médico já conversou com vocês? O quê o médico conversou com vocês? Então a partir daí eu tento entender até onde eles sabem, o quê que eles sabem, se o médico falou alguma coisa que vai beneficiar ou atrapalhar. (Amarelo Ocre)

\section{Manejos de Situações Difíceis com Base nos Instru- mentos de Enfrentamento das Dificuldades}

As falas mostraram que os manejos envolvem: ter noção da realidade e entender que as pessoas morrem o tempo todo, em todo lugar; aceitar/se resignar diante do que considera "batalha perdida"; entender o papel social do entrevistador; se apegar com os filhos em casa; fazer uma oração e pedir a Deus para receber aquela alma; e, respirar fundo.

Amarelo de Cádmio classifica como situação frequentemente difícil "encontrar noradrenalina em veia periférica, encontrar o paciente abandonado sendo comido por moscas varejeiras, com fraldas sujas", o que acaba criando conflitos entre familiares e a equipe do hospital notificador. Neste momento, se revolta com esta situação, mas sabe que se abordar a equipe de maneira grosseira, perderá estes profissionais os quais os coordenadores da CNCDO também dependem para iniciar a notificação. Com isso, maneja esta situação de maneira política como coloca a seguir:

Você também tem muito jogo político em off. Eu não posso chegar lá no hospital dizendo: Você abandonou essa pessoa, está sujo, imundo! Não! [...]. Nesse momento eu vou respirar fundo, eu vou respirar fundo e vou conversar com aquela equipe que está ali [...] Acabo de certa forma, amenizando este conflito da família com a unidade. (Amarelo de Cádmio)

Tendo em vista a realidade posta nos hospitais notificadores do estado do Rio de Janeiro, muitas adversidades podem ser observadas e vivenciadas por aqueles que trabalham e são atendidos nesses locais. Falta de material humano, falta de infraestrutura logística e material são algumas das dificuldades que profissionais de saúde e familiares enfrentam na busca de um atendimento em saúde eficaz, equânime e integral como propõe o Sistema Único de Saúde Brasileiro.
No entanto, manter tais princípios com qualidade é uma tarefa complexa que envolve desde a política local e financiamento destinado à saúde, até a educação da população, papel este que também está contido nas atividades de um grande hospital.

\section{(Não) Manejo de Situações Difíceis - "Não Sei, Nunca Parei para Pensar Nisso"}

Esta categoria surgiu da fala de um sujeito que informou não ter se deparado com este questionamento anteriormente, por isso não havia parado para refletir acerca deste assunto, o que traduz a dificuldade que alguns sujeitos evidenciaram em fazer o exercício de olharem para seus próprios mecanismos de enfrentamento e de manejo das situações, não somente as difíceis.

\section{DISCUSSÃO}

O hospital notificador representou o reduto das situações difíceis vivenciadas pelos coordenadores avançados em transplantes. Por meio da linguagem que caracteriza a relação do ser com o mundo, diferenciando-o de todos os demais seres vivos, foi possível conhecer a tradição do preparo emocional dos profissionais que realizam a entrevista familiar para doação de órgãos. Gadamer (2008) afirma que a linguagem caracteriza a relação do Ser com o mundo, diferenciando-o de todos os demais seres vivos.

O ambiente inadequado, a não-formação específica e a má assistência formam uma tríade reforçada por outros estudos que citam o local da entrevista, a assistência prestada ao potencial doador e aos familiares (Santos e Massarollo, 2011), e a necessidade de capacitação profissional para conhecer, identificar e lidar com fatores que facilitam ou dificultam o diálogo com os familiares (Santos, Massarollo, e Moraes, 2012), como aspectos dificultadores do desenvolvimento da entrevista familiar. Ao trazerem em suas falas estas situações, os participantes, representantes do Ser, tornam-se livres face ao mundo que os circundam (Gadamer, 2008), pois seus relatos permitem abertura para interpretá-los. Desta maneira, revelam ideias e situações empoderados de um conhecimento pertencente ao seu universo, que constitui parte do mundo.

Sobre isso o Guía de buenas prácticas en el proceso de donación de órganos (Organización Nacional De Trasplantes [ONT], 2011) enfatiza dentre outras questões, a necessidade de uma formação específica em Comunicação de Más Notícias e a promoção de um atendimento humanitário e respeitoso aos familiares, o que reforça a relevância destes elementos na composição do trabalho de doação. 
Desta forma, estabelecer uma assistência adequada durante a internação, somada ao esclarecimento do que é a morte encefálica antes da solicitação da doação, adotar uma postura sensível do entrevistador de modo que este promova o acolhimento da família e a utilização do tempo necessário na abordagem familiar são entendidos como aspectos favoráveis a doação (Kesselring, Kainz, \& Kiss, 2007) e podem ser colocados em prática para que os obstáculos destacados sejam transpostos. Outros aspectos que auxiliam na promoção da saúde mental dos profissionais, são que: devem ser adotadas pelos estabelecimentos de saúde políticas que estejam voltadas para a melhoria da qualidade de vida e de saúde física e mental dos trabalhadores e que busquem adaptar o trabalhador aos esforços no trabalho (Rodrigues, Freitas, Assunção, Bassi, e Medeiros, 2013).

Quanto aos manejos das situações observadas foi possível observar naquele relacionado a conduta do entrevistador que alguns dos coordenadores avançados em transplantes, traçam um objetivo para além da situação vivenciada na entrevista que é de pensar no receptor e nos benefícios que aquela doação trará para outra (s) família (s). Com isso, veem uma espécie de justificativa benevolente na ação implementada, o que lhes fortalece no enfrentamento das situações difíceis. A este respeito, estudo com profissionais de Unidade de Terapia Intensiva (UTI) revela que os significados do trabalho estão atrelados à contribuição social e a responsabilidade e/ ou troca. Afirma que, quando o profissional de saúde atende a pacientes que verdadeiramente necessitam de assistência, é algo visto positivamente. Desta maneira, a assistência em saúde, em alguns casos, se mostra como fonte de auxílio à manutenção da saúde mental, podendo se configurar como um fator de promoção à saúde mental (Silva et al., 2015; Baasch e Laner, 2011). Nesta linha, o profissional percebe que seu trabalho é extremamente significativo, por estar fazendo um bem, algo bom, que pode gerar vidas (Lima, 2013) e isso o possibilita um feedback positivo em relação ao complexo trabalho que é realizado no processo de doação de órgãos. O retorno positivo quanto às investidas laborais o motiva, fazendo-o acreditar mais no processo e também em si mesmo, o que corrobora para a manutenção de sua saúde mental (Fonseca e Tavares, 2014).

Junto a isso, nos manejos relacionados aos aspectos emocionais, estes sujeitos procuram respeitar a decisão familiar se disponibilizando a ouvi-los e, neste momento, estes profissionais recebem despejos de tensões, frustrações, insatisfações dos familiares, principalmente se $o$ atendimento na unidade notificadora não foi satisfatório.
Desta forma, o contato com familiares nesta situação traz mais cargas emocionais aos entrevistadores que precisam lançar mão de, além da escuta terapêutica, alguns dos cuidados caritativos como os propostos por Jean Watson, ao fazerem uso do seu sistema de valores humanísticos e altruísticos, da sensibilidade para si e para os outros, precisando ainda desenvolver as relações de auxílio, confiança, cuidado com os familiares e neste contexto, expressar seus sentimentos e emoções, positivas e negativas quanto a esta situação (Watson, 1994). Outro ponto a se destacar neste tipo de manejo, é a relação de abafamento emocional travestida na expressão de profissionalismo ao lidar com os familiares, ao se afirmar que para se passar uma sensação de segurança é preciso que o profissional não se permita ser emotivo. Seguindo este tipo de relação com as emoções, soma-se a expressão utilizada "Não sei, nunca parei para pensar nisso" que demonstra que aspectos relacionados ao olhar para si, auto compreensão e atenção as reações emocionais não são postos em prática. A respeito destes dois últimos modos de enfrentar/lidar com as próprias emoções, Casassus (2009) explana que a pessoa que não reconhece a emoção ou o estado de ânimo em que se está ou tem uma vaga consciência dele, que se sente mal e não se dá conta, sendo irritável, pessimista ou desanimada sem assumir responsabilidade por esse estado, achando que o mundo e a vida são assim, é denominada como Incompetente Emocional. Este conceito representa um sinal de pouco contato consigo mesmo/autoconhecimento. O autor traz que a Educação Emocional (Casassus, 2009) essencialmente é um movimento de autoconhecimento e auto concessão emocional, por isso ao agir em favor de suas emoções reconhecendo-as e ventilando-as, o profissional se permite, a partir disso, se entender e se respeitar, agindo assim, melhor e mais assertivamente diante da situação difícil, o que o auxilia na manutenção de sua saúde mental (Fonseca e Tavares, 2015), tendo a possibilidade de retomar sua atividade mais firme e seguro.

No manejo relacionado aos familiares os coordenadores avançados percebem os parentes como um agente complementar às informações oferecidas pela unidade notificadora. É como se fossem uma espécie de raio- $x$ do atendimento oferecido pelo hospital em que se encontra o possível doador e também de seu próprio desempenho laboral. Indicam ainda que uma informação desencontrada ou oferecida num momento anterior ao que deveria ser declarado, pode ser fatal para o aceite ou não, dos familiares à doação. 
Portanto, falar da doação antes do protocolo de avaliação de morte encefálica ser fechado, por exemplo, pode dar desde esperanças de doação aos familiares - o que pode não se concretizar caso o protocolo não confirme a morte encefálica ou o doador faça uma parada cardíaca neste ínterim - até criar a sensação de revolta nos mesmos, pois seria a antecipação do quadro de óbito, sem as devidas comprovações clínicas.

Assim, como afirma o Guía de buenas prácticas en el proceso de donación de órganos (ONT, 2011) é imprescindível a informação de comunicação das más notícias ser transmitida para as equipes que lidarão com os casos de possíveis e potenciais doadores. Mas, para além da formação técnica, é preciso que os profissionais também tenham sensibilidade, empatia, escuta sensível, promovam o acolhimento dos familiares (Silva et al., 2015). Este fato não somente mudaria os aceites ou negativas familiares à doação, mas deixaria as equipes mais seguras e bem informadas quanto aos passos da doação e aos momentos mais oportunos de acessar os parentes. Por fim, no manejo que lança mão dos instrumentos próprios de enfrentamento foi possível observar o quanto estes profissionais usam da diplomacia ao dialogarem com familiares não satisfeitos com o atendimento oferecido pela unidade notificadora ou mesmo aqueles que não aceitam ou entendem o diagnóstico de morte encefálica (Torres e Lage, 2013), situação comumente vivenciada por quem realiza a entrevista. A estratégia diplomática relacional busca dirimir o desgaste e os conflitos, seja com os parentes ou com a equipe que oferece um mau atendimento. Os participantes demonstram com isso, fazerem uso da tradição pensada por Gadamer (2008), pois utilizam elementos de suas reservas emocionais e estratégias para lidarem com o outro e, muitas vezes, tais elementos são representados de ações e emoções inconscientes. Neste sentido, Gadamer (2008) afirma ainda que a existência do Ser se dá em um horizonte experiencial que contém concomitantemente a condicionalidade da finitude humana, a tradição constituída pelo contexto sócio-histórico e a incondicionalidade da abertura do Ser.

\section{CONCLUSÃO}

Embora o papel das unidades notificadoras seja de grande relevância, pois é neles que são identificados os possíveis doadores, questões como as que emergiram nesse estudo, que envolvem a falta de um ambiente reservado para a realização das entrevistas familiares, equipe acolhedora e profissionais capacitados, representam obstáculos a serem transpostos pelo país que possui o maior sistema público de transplantes do mundo
(Portal Brasil, 2015). Os manejos das situações difíceis trazidas pelos participantes, demonstraram que estes usam grande parte de recursos não somente técnicos, mas principalmente, próprios/subjetivos de enfrentamento, estando a relação com as emoções em destaque, seja com os familiares do potencial doador, seja com a equipe da unidade notificadora ou mesmo consigo mesmos na atividade da entrevista familiar.

Deste modo, é relevante atentar para a formação/educação emocional destes profissionais que lidam frequentemente com dilemas morais e que enfrentam em suas realidades laborais constantes desafios em prol da causa da doação de órgãos.

\section{IMPLICAÇÕES PARA A PRÁTICA CLÍNICA}

A promoção do cuidado emocional dos coordenadores avançados em transplantes, pode impactar não somente na qualidade das entrevistas familiares, aumentando a possibilidade do aceite para doação de órgãos, mas também pode valorizar pequenos enfrentamentos e manejos que guardam significação positiva para o profissional, influenciando diretamente em seu autoconhecimento e manutenção de sua saúde mental.

\section{REFERÊNCIAS BIBLIOGRÁFICAS}

Baasch, D., e Laner, A. S. (2011). Os significados do trabalho em unidades de terapia intensiva de dois hospitais brasileiros. Ciência \& Saúde Coletiva, 16(Suppl. 1), 1097-1105. Disponível em http://www. scielo.br/scielo.php?script $=$ sci_arttext $\&$ pid $=S 1413$ $81232011000700041 \& \operatorname{lng}=$ en

Casassus, J. (2009). Fundamentos da educação emocional. Brasília: UNESCO, Liber Livro Editora.

Cuiabano, R. S. (2010). Morte encefálica no contexto da doação de órgãos. Cuiabá, Mato Grosso.

Decreto $n^{\circ}$ 2268/97. Regulamenta a Lei no 9.434, de 4 de fevereiro de 1997, que dispõe sobre a remoção de órgãos, tecidos e partes do corpo humano para fim de transplante e tratamento, e dá outras providências. Disponível em http://www.planalto.gov.br/ccivil_03/decreto/1997/d2268.htm

Fonseca, P. I. M. N., e Tavares, C. M. M. (2015). O manejo das emoções dos coordenadores em transplantes na realização da entrevista familiar para doação de órgãos. Revista Portuguesa de Enfermagem de Saúde Mental (Spe. 2), 39-44. 
Fonseca, P. I. M. N., e Tavares, C. M. M. (2014). Emotional preparedness of health professionals in Family interviews: A hermeneutic study. Online Brazilian Journal of Nursing, 13(4), 496-506. Disponível em http://www. objnursing.uff.br/index.php/nursing/article/view/4690

Gadamer, H. G (2008). Verdade e método: Traços fundamentais de uma hermenêutica filosófica (10 $10^{\mathrm{a}} \mathrm{ed}$.). Petrópolis: Vozes.

Kesselring, A, Kainz, M, \& Kiss, A. (2007). Traumatic memories of relatives regarding Brain Death, request for organ donation and interactions with professionals in the ICU. American Journal of Transplantion, 7, 211-217. Disponível em http://www.ncbi.nlm.nih.gov/ pubmed/17227569

Lima, A. A. (2013). Doação de órgãos para transplante: Conflitos éticos na percepção do profissional. O Mundo da Saúde, 36(1), 27-33. Disponível em http://bvsms. saude.gov.br/bvs/artigos/mundo_saude/doacao_orgaos_transplante_conflitos_eticos.pdf

Moraes, E. L. (2013). Vivência de enfermeiros no processo de doação de órgãos e tecido para transplante (Tese de Doutorado) São Paulo, Brasil. Disponível em www. teses.usp.br/teses/disponiveis/7/7140/tde-10092013$184153 /$

Organización Nacional De Trasplantes. (2011). Guía de buenas prácticas en el proceso de la donación de órganos. Ministerio de Sanidad, Política Social e Igualdad.

Pierro, B. (2015). Doação de órgãos: A arte de dar más notícias. Revista Pesquisa Fapesp, 237. Disponível em http://revistapesquisa.fapesp.br/2015/11/17/doacaode-orgaos-a-arte-de-dar-mas-noticias/

Portal Brasil. (2015, janeiro 5). Sistema Único de Saúde financia 95\% dos transplantes no Brasil. Disponível em http://www.brasil.gov.br/saude/2015/01/sistema-unicode-saude-financia-95-dos-transplantes-no-brasil

Portaria $n^{\circ} 2600 / 09$. Aprova o regulamento técnico do Sistema Nacional de Transplantes. Disponível em http:// www.brasilsus.com.br/legislacoes/gm/101249-2600. html
Programa Avançado em Coordenação de Doação/ Transplante. (2007). Manual do Coordenador de Doação. Barcelona: Universitat de Barcelona.

Rodrigues, C. S, Freitas, R. M., Assunção, A. A., Bassi, I. B., e Medeiros, A. M. (2013). Absenteísmo-doença segundo autorrelato de servidores públicos municipais em Belo Horizonte. Revista Brasileira de Estudos de População, 30(Suppl.). Disponível em http://www.scielo.br/pdf/rbepop/v30s0/09.pdf

Roza, B. A. (2005). Efeitos do processo de doação de órgãos e tecidos em familiares: intencionalidade de uma nova doação (Tese de Doutorado). São Paulo, Brasil. Disponível em www.abto.org.br/abtov03/Upload/ file/.../tese_doutorado_bartira_roza.pdf

Santos, M. J., e Massarollo, M. C. K. (2011). Fatores que facilitam e dificultam a entrevista familiar no processo de doação de órgãos e tecidos para transplante. Acta Paulista de Enfermagem, 24(4), 472-478. doi: http:// dx.doi.org/10.1590/S0103-21002011000400005

Santos, M. J., Massarollo, M. C. K., e Moraes, E. (2012). Entrevista familiar no processo de doação de órgãos e tecidos para transplante. Acta Paulista de Enfermagem, 25(5), 788-794. doi: http://dx.doi.org/10.1590/S010321002012000500022

Silva, T. N., Tavares, C. M. M., Fonseca, P. I. M. N, Muniz, M. P., Paiva, L. M., Augusto, V. O. (2015). Promoting the mental health of health professionals. Journal of Research Fundamental Care Online, 7(4), 3496-3505. Disponível em http://www.seer.unirio.br/index.php/ cuidadofundamental/article/view/5005/pdf_1743

Torres, J .C., e Lage, A. M. V. (2013). Manifestações psicológicas de familiares com pacientes em morte encefálica. Revista de Psicologia, 4(1), 38-51. Disponível em http://www.periodicos.ufc.br/index.php/psicologiaufc/ article/viewFile/789/766

Watson, J. (1994). Applying the art and science of human caring. In M. McEwen \& E. M. Wills, Bases teóricas para enfermagem ( $2^{\mathrm{a}}$ ed.). Porto Alegre: Artmed. 